\title{
Serum level of Pentraxin 3 in Patients with Acne Vulgaris
}

A.A.Ibrahim ${ }^{1}$, A.I.Mustafa ${ }^{1}$, O.S.El-Shimi ${ }^{2}$ and A.M.Abd El motelib ${ }^{1}$

${ }^{1}$ Dermatology, Venereology and Andrology Dept., Faculty of Medicine, Benha Univ., Benha, Egypt

${ }^{2}$ Clinical and Chemical Pathology, Faculty of Medicine, Benha Univ., Benha, Egypt

E-Mail:abeer516@gmail.com

\begin{abstract}
Acne vulgaris is a chronic inflammatory disease of the pilosebaceous units. It is a pleomorphic disorder with multifactorial pathogenesis, affects virtually all individuals at least once. PTX3 represent a rapid biomarker for primary local activation of innate immunity and inflammation. to assess serum level of pentraxin 3 in patients with acne vulgaris. This instance control examine might have been directed on 55 patients anguish from av (Group An) What's more 30 Obviously solid people for matched period Furthermore sex as An control assembly (Group B). Constantly on patients were subjected to full history taking, complete clinical examination Furthermore serum level about Pentraxin3 (PTX3). The patients imply period might have been 21 years, they were 20 guys (36. 4\%) Furthermore 35 females (63. 6\%). Twenty four patients required sudden passing onset (43.6\%), While 56. 4\% required gradual onset. Same time 38 (69. $1 \%$ ) patients required progressive course. Imply span of malady for concentrated on patients might have been 4.7 years, face might have been influenced altogether cases55(100\%) patients taken after Toward over 25 (45.5\%)patients What's more midsection 12 (21. 8\%) patients. Skin break out seriousness might have been evaluated On the whole examined cases; gentle situations spoken to $29.1 \%$; moderate situations spoke to $38.2 \%$ same time extreme level might have been exhibit Previously, 32. 7\%. Skin inflammation vulgaris patients indicated essentially higher fixation of Pentraxin 3 (Ptx 3) The point when contrasted with control bunch (P. 0. 011). Skin inflammation vulgaris patients indicated essentially higher centralization for Pentraxin 3.
\end{abstract}

Keywords: Pentraxin 3, Acne Vulgaris, PTX3.

\section{Introduction}

Skin inflammation vulgaris will be a Ceaseless incendiary malady of the pilosebaceous units. It will be An pleomorphic issue for multifactorial pathogenesis, influences essentially every one people no less than When. Occurrence peaks over 18-year-olds, Be that as generous numbers of 20- with 40-year-olds Additionally create the sickness. Those impacts about skin break out ought not a chance to be underestimated. It camwood persimmon tree for years; handle distortion What's more lasting scarring; and need noteworthy psychosocial results. The degree Also seriousness about these impacts underline the vitality of giving sufficient therapy, which produces acceptable outcomes By and large [1].

It's described Toward open alternately shut comedones What's more incendiary papules, pustules, nodules, or cysts. Four significant variables connected with the pathogenesis for skin break out would expanded sebum production, follicular hyperkeratinization, Propionibacterium acnes proliferation, Furthermore aggravation [2].

It principally comes about starting with those overproduction for oils in the sebaceous follicles of the skin, which need aid intensely discovered around the face and upper once more. Alterations should follicular development, including hyper keratinization, help skin break out improvemen. The gram-positive anaerobe P. Acnes inhabits the skin and sebaceous follicles. P. Acnes discharge proteins (e. G. , lipases, proteases) that would answerable for the AV-associated aggravation and the formation of incendiary mediators. These incendiary mediators thusly cause stopped follicles should get inflamed, Along these lines prompting the incendiary lesions think Likewise papules, pustules, Furthermore nodules [3].
Skin break out will be principally an incendiary disease, testing the present terminology for noninflammatory versus incendiary skin break out lesions and suggesting that those terminology will be old fashioned What's more inaccurate. The proof over backing of skin break out Concerning illustration a incendiary malady Additionally need clinical implications, in that mitigating medications used to treat the ailment could a chance to be expected on push impacts against the sum lese greatness stages, albeit through dissimilar instruments for anti-inflammation [4].

Aggravation need in length been perceived as critical in the pathogenesis of acne; however, it might have been recognized a optional occasion. Investigations again as long as decade have showed a focal part to aggravation in the advancement from claiming skin break out lesions What's more need opened new chances to restorative intercession. Comprehension the part of aggravation in the improvement from claiming skin inflammation vulgaris is significant for dermatologists, as it might effect our medicine decisions Also recognize extra focuses to new medication modalities [5].

Pentraxin 3 may be the initial distinguished Furthermore to date those The greater part vital protein of a as of late perceived gathering known as long pentraxins. Previously, A large number aspects, those structure Also capacity for PTX3 resembles that from claiming short (or classical) pentraxins, i. E. , c-touchy protein and the serum amyloid $\mathrm{p}$ part. There are, however, a few vital contrasts between those two bunches about pentraxins. The greater part of the over pentraxins take an dynamic a major aspect On first-line guard of the group against attacking pathogenic creatures Also in the freedom of the host's own apoptotic units. 
Pentraxin 3 (PTX3), Sporadically Likewise alluded with as TSG-14 (TNF-stimulated gene 14) [6].

PTX3 will be transformed in the skin Furthermore other organs, particularly in the heart Also striated muscle, and in addition in the lungs, ovarium, liver Furthermore thymus. For Mobile cultures, PTX3 is generated Toward TNF $\alpha$ or IL-1 $\beta$ invigorated fibroblasts, endothelial cells, monocyte-macrophage Mobile lines What's more Toward those dendritic phones. Additionally, in monocyte macrophage cell lines, PTX3 structuring is improved by bacterial lipopolysaccharide Also by parts from claiming mycobacterial Mobile membranes alluded should Similarly as liparabinomanans. PTX3 shaping in units of the monocyte macrophage ancestry may be repressed by IFN $\gamma$ [7].

PTX3 speak to An fast biomarker to essential neighborhood actuation for characteristic safety What's more aggravation [8].

\section{Patients and methods}

This consider meant with survey serum level about pentraxin 3 Previously, patients with skin inflammation vulgaris.

\subsection{Patients Furthermore strategies}

This the event control consider might have been led around 55 patients anguish from av (Group An) and 30 clearly sound people for matched agdistis and sex Concerning illustration a control gathering (Group B). Patients were recruited starting with the outpatient facility for dermatology Furthermore Andrology Branch for Benha college doctor's facilities betweenApril Furthermore december 2018.

The study might have been endorsed Toward those neighborhood ethic council from claiming Benha employees of medication. A educated assent might have been got starting with each distinctive in front of example gathering.

Consideration Criteria. Patients with distinctive degrees from claiming seriousness for av as stated by worldwide skin break out evaluating framework (GAGS) [9].

Avoidance Criteria. - unending incendiary immune system infections (e. G. Psoriasis, Eczema\& Behçet's disease).

- systemic illnesses (e. G. Unending renal diseases\& atherosclerotic cardiovascular disease).

- Patients utilizing skin break out topical anesthesia medication for 2 weeks Also systemic medication to skin break out for 1 month in front of initiating those consider.
- Patients for immune system infections for example, such that sle. - Subjects more youthful over 15 alternately elders.

The sum patients were subjected will full historical backdrop taking, finish clinical examination and serum level from claiming Pentraxin3 (PTX3).

Analysis from claiming av might have been settled on on the premise of the patient's historical backdrop and the ordinary clinical features from claiming noninflammatory lesions form, including shut (whiteheads) What's more open (blackheads) comedones, and incendiary lesions including papules, pustules, nodules or cysts on the face, midsection What's more upper once more.

Patients were graded as stated by GAGS under three groups: gentle (16 patients), direct (21 patients) Also extreme (18 patients).

The aggregate seriousness score might have been inferred from those summational from claiming six territorial subscores. Each might have been inferred Toward multiplying those figure for every region; (factor for brow and each cheek might have been 2, jaw and nose might have been 1 Furthermore midsection Also upper over might have been 3); Toward those practically intensely weighted lese greatness inside each district (1 to comedones, 2 to papules, 3 to pustules and 4 for nodules). An score of (1-18) will be recognized mild; (19-30) moderate; (31-38) severe; and >39 really extreme [9].

\subsection{Statistical analysis}

The collected data was revised, coded, tabulated and introduced to a PC using Statistical package for Social Science (IBM CorP. Released 2011. IBM SPSS Statistics for Windows, Version 20.0. Armonk, NY: IBM CorP.). Data were presented and suitable analysis was done according to the type of data obtained for each parameter. Shapiro test was done to test the normality of data distribution. Significant data was considered to be nonparametric. Mean Standard deviation $( \pm$ SD) for parametric numerical data. Frequency and percentage of non-numerical data. Student $\mathrm{T}$ Test was used to assess the statistical significance of the difference between two study group means. Chi-Square test was used to examine the relationship between two qualitative variables.

\section{Results}

The present study was conducted on 55 cases with acne, their mean age was 21 years, they were 20 males $(36.4 \%)$ and 35 females $(63.6 \%)$. In addition to 30 healthy control group of matched age and gender Table (1).

Table (1) Comparison of age and gender between all studied groups.

\begin{tabular}{|c|c|c|c|c|c|c|c|}
\hline & & & \multicolumn{2}{|c|}{$\begin{array}{c}\text { Control } \\
\mathbf{N}=\mathbf{3 0}\end{array}$} & \multicolumn{2}{|c|}{$\begin{array}{l}\text { Acne } \\
N=55\end{array}$} & $\mathbf{P}$ \\
\hline \multirow{3}{*}{$\begin{array}{l}\text { Age (years) } \\
\text { Sex }\end{array}$} & \multirow{3}{*}{$\begin{array}{c}\text { Male } \\
\text { Female }\end{array}$} & mean \pm SD & \multicolumn{2}{|c|}{$20.2 \pm 3.2$} & \multicolumn{2}{|c|}{$21 \pm 5.1$} & 0.426 \\
\hline & & $\mathrm{N}(\%)$ & 10 & 33.3 & 20 & 36.4 & 0.780 \\
\hline & & $\mathrm{N}(\%)$ & 20 & 66.7 & 35 & 63.6 & 0.780 \\
\hline
\end{tabular}

$\mathrm{SD}$, standard deviation; age is compared using t test; gender is compared using chi square test. 
Twenty four patients had sudden onset (43.6\%), While $56.4 \%$ had gradual onset. While 38 $(69.1 \%)$ patients had progressive course. Mean duration of disease in studied patients was 4.7 years, Face was affected in all cases55(100\%) patients followed by back $25(45.5 \%)$ patients and chest $12(21.8 \%)$ patients. Acne severity was assessed in all studied cases; mild cases represented $29.1 \%$; moderate cases represented $38.2 \%$ while severe degree was present in $32.7 \%$.

Acne vulgaris patients showed significantly higher concentration of Pentraxin 3 (Ptx 3) when compared to control group (P. 0.011) as shown in Table (2).

Table (2) Comparison of Pentraxin 3 concentration between studied groups.

\begin{tabular}{|c|c|c|c|}
\hline Variable & $\begin{array}{c}\text { Control } \\
\mathbf{N}=\mathbf{3 0}\end{array}$ & $\begin{array}{l}\text { Acne } \\
\mathrm{N}=55\end{array}$ & $\mathbf{P}$ \\
\hline & mean \pm SD & mean \pm SD & \\
\hline Pentraxin 3 (ng/ml) & $4.4 \pm 0.6$ & $6.2 \pm 1.1$ & 0.011 \\
\hline
\end{tabular}

\section{Discussion}

The present ponder outcomes demonstrated that, serum level of PTX3 might have been essentially higher to av patients in examination should sound controls $(\mathrm{P}=$ $<0.011)$.

In spite of this marker might have been not concentrated on done skin break out patients previously, then the available contemplate is those primary examine to assess serum PTX3 level done av patients, it needed been concentrated on Previously, Numerous skin infections for example, Behçet's ailment [10], Psoriasis [11], Multi bacillary patients (MB) [12], little vespula vulgaris vasculitis [13].

The present study demonstrated comparative outcomes to study led by [10]; they accounted for that PTX3 plasma levels fundamentally higher in patients for Behçet's malady (BD) over the individuals for sound controls $(\mathrm{p}<0.05)$.

PTX3 serum levels were secondary clinched alongside $\mathrm{mb}$ patients without response yet constant done patients who created enl response. To contrast, mb patients who created RR required low levels about PTX3 former should and during those onset of the occasion. PTX3 might have been in reality downregulated then afterward beginning antireactional medicine clinched alongside correspondence for those clinical change from claiming enl patients. On account PTX3 colocalized with MPO, a particular neutrophilic marker, On enl lesions, the higher outflow for PTX3 Might be identified with those gigantic vicinity for neutrophils. [12].

Our theory is that PTX3 might assume a paramount part in the pathogenesis of av. Past investigations bring shown PTX3 as a prognostic biomarker Previously, patients with systemic Furthermore vascular aggravation [14].

P. Acnes actuate the outflow of the proinflammatory cytokines IL-8, IL-12, IL-1 $\alpha$, IL-1 $\beta$, Furthermore tumor putrefaction element alpha Eventually Tom's perusing intrinsic cells, for example, such that keratinocytes Also monocytes, through the TLR2 statement for sensing of peptidoglycans What's more lipopolysaccharides [15].

Toll similar to receptor need emrerged Similarly as An way controller about host reactions to contamination [16]. This transmembrane protein need a cytoplasmic bit that is homologous of the IL- 1 receptor What's more
Therefore Might trigger a indicating course that activates atomic factor-k $\beta$. In vivo study by [17], exhibited that these occasions happen for incendiary lesions from claiming patients with facial skin break out. Incendiary cytokines that attempting by means of autocrine Also paracrine instruments through their particular receptors, intensify those indicating pathways that initiate those activator protein (AP)-1 interpretation variable. Actuation about AP-1 induces [18].

Those mossycup oak conspicuous PTX3 promotors are activator protein-1 (AP-1), atomic factor-kappa b (NF-kB), Also particular promoter figure 1 (SP1) [19]. Briefly, AP-1 enhances basal interpretation for PTX3, while the NF- $\kappa$ B tying site may be agent in the light of incendiary cytokines TNF- $\alpha$ or IL-1 $\beta$. [20].

Raised serum PTX3 levels need aid supported Toward de novo generation Eventually Tom's perusing endothelial cells, monocytes, macrophages, What's more dendritic units because of the opposition should actuation of Toll-like receptor (TLR) 2, and additionally incendiary jolts [21].

Separated starting with those era about PTX3 to a light of incendiary stimuli, there will be likewise a constitutive, instant manifestation about PTX3 which may be put away over particular (lactoferrin+) granules from claiming neutrophils. Then afterward these phones bring been actuated by proper stimuli, this preformed amount of PTX3 may be discharged under those extracellular space. After these phones need been actuated Eventually Tom's perusing fitting stimuli, this preformed measure for PTX3 will be discharged under those extracellular space [22].

P. Acnes produces neutrophilic chemotactic variables which pull in neutrophils to sebaceous follicles bringing about arrival of hydrolases from neutrophils on disturb those follicular dividers [15].

PTX3 will be included in supplement actuation through the classical,lectin, Also elective pathways. PTX3 ties the main part from those established supplement cascade, C1q, modulating the actuation of the traditional pathway. Previously, addition, PTX3 interacts with component $\mathrm{H}$, the fundamental dissolvable controller of the elective pathway about supplement activation, pushing variable $\mathrm{H}$ affidavit with respect to 
PTX3-coated surfaces Also keeping overstated supplement actuation. Finally, PTX3 synergizes for ficolin-2 On distinguishing pathogens Also activating supplement affidavit [23]. Those supplement framework actuation need been demonstrated to a chance to be included in the pathogenesis from claiming skin inflammation vulgaris [24].

\section{Conclusion}

Acne vulgaris is a chronic inflammatory disease of the pilosebaceous units. It is a pleomorphic disorder with multifactorial pathogenesis, affects virtually all individuals at least once. PTX3 represent a rapid biomarker for primary local activation of innate immunity and inflammation. Acne vulgaris patients showed significantly higher concentration of Pentraxin3.

\section{References}

[1] S.S.Oberemok, A.R.Shalita, "Acne vulgaris, I: pathogenesis and diagnosis," CUTIS-NEW YORK-; Vol.70( 2), PP. 101-105, 2002.

[2] C.B.Archer, S.N.Cohen, S.E.Baron, "Practitioners BAoDaRCoG," Guid. diagnosis Clin. Manag. acne. Clin Exp Dermatol;Vol.37, PP. 1-6, 2012.

[3] B.Dreno, "Understanding innate immunity and inflammation in acne: implications for management," J. Eur. Acad. Dermatology Venereol; Vol.29, PP. 3-11, 2015.

[4] E.A.Tanghetti, "The role of inflammation in the pathology of acne," J. Clin. Aesthet. Dermatol; Vol.6( 9), P. 27, 2013.

[5] L.F.G.Stein, "What's new in acne and inflammation?," J. drugs dermatology JDD; Vol.12 ( 6), PP. 67-9, 2013.

[6] B.Bottazzi, "The long pentraxin PTX3: from innate immunity to ischemic heart disorders," in International Congress Series; Vol.1262, PP. 63$66,2004$.

[7] G.Peri, "PTX3, A prototypical long pentraxin, is an early indicator of acute myocardial infarction in humans," Circulation;Vol.102( 6), PP. 636-641, 2000.

[8] A.Inforzato, "The long pentraxin PTX3 at the crossroads between innate immunity and tissue remodelling," Tissue Antigens; Vol.77( 4), PP. 271282, 2011.

[9] A.Doshi, A.Zaheer, and M.J.Stiller, "A comparison of current acne grading systems and proposal of a novel system," Int. J. Dermatol; Vol.36( 6), PP. 416-418, 1997.

[10] B.A.Mesci, "Can Pentraxin-3 be a Candidate Marker in the Follow-Up of the Patients With Behçet's Disease?," Arch. Rheumatol;Vol.32(2), PP. 91, 2017.
[11] V.Bevelacqua . "Long pentraxin 3: a marker of inflammation in untreated psoriatic patients," Int. J. Mol. Med; Vol.18(3), PP. 415-423, 2006.

[12] M.A.Mendes, "Elevated pentraxin-3 concentrations in patients with leprosy: potential biomarker of erythema nodosum leprosum," J. Infect. Dis; Vol.216(12), PP. 1635-1643, 2017.

[13]F.Fazzini, "PTX3 in small-vessel vasculitides: an independent indicator of disease activity produced at sites of inflammation," Arthritis Rheum. Off. J. Am. Coll. Rheumatol;Vol.44(12), PP. 2841-2850, 2001.

[14] S.Suzuki, "Pentraxin 3, a new marker for vascular inflammation, predicts adverse clinical outcomes in patients with heart failure," Am. Heart J; Vol.155(1), PP. 75-81, 2008.

[15] M.Tassavor, M. J. Payette, "Estimated cost efficacy of US Food and Drug Administration-approved treatments for acne," Dermatol. Ther; Vol.32(1), PP. 12765, 2019.

[16] R.Kapetanovic , J.-M. Cavaillon, "Early events in innate immunity in the recognition of microbial pathogens," Expert Opin. Biol. Ther;Vol.7(6), PP. 907-918, 2007.

[17] S.Jugeau, "Induction of toll-like receptors by Propionibacterium acnes," Br. J. Dermatol; Vol.153(6), PP. 1105-1113, 2005.

[18]P.T.Liu, "CD209+ macrophages mediate host defense against Propionibacterium acnes," J. Immunol; Vol.180(7), PP. 4919-4923, 2008.

[19]P.Kunes, Z.Holubcova, M.Kolackova, J. Krejsek, "Pentraxin 3 (PTX 3): an endogenous modulator of the inflammatory response," Mediators Inflamm; Vol.2012(3), PP. 13-26, 2012.

[20]B.Han, "TNF $\alpha$-induced long pentraxin PTX3 expression in human lung epithelial cells via JNK," J. Immunol; Vol.175(12), PP. 8303-8311, 2005.

[21] A.Doni, "Regulation of PTX3, a key component of humoral innate immunity in human dendritic cells: stimulation by IL-10 and inhibition by IFN- $\gamma$," J. Leukoc. Biol; Vol.79(4), PP. 797-802, 2006.

[22] S.Jaillon, "The humoral pattern recognition receptor PTX3 is stored in neutrophil granules and localizes in extracellular traps," J. ExP. Med; Vol.204(4), PP. 793-804, 2007.

[23] Y.J.Ma, "Synergy between ficolin-2 and pentraxin 3 boosts innate immune recognition and complement deposition," J. Biol. Chem; Vol.284(41), PP. 28263 28275, 2009.

[24] C.Li, J.Chen, W.Wang, M.Ai, Q. Zhang, L. Kuang, "Use of isotretinoin and risk of depression in patients with acne: a systematic review and metaanalysis," BMJ Open; Vol.9(1), P. 021549, 2019. 